Association of Arab Universities

Journal of Engineering Sciences

مجلة اتحاد الجامعات العربية للار اسات والبحوث الهندسية

التنمية السياحية المستدامة في الاماكن التر اثية الحضريةــ القتلة كحالة در اسية

هلى عادل عبل الحمبي 1*، أسامة عبد المنعم التميمي 2

اقسم هندسة العدارة، جامعة بغداد، dolaarch@yahoo.com

eng_usama_uat@yahoo.com فسم هندسة العمارة، جامعة بغداد،

dolaarch@yahoo.com 'الباحث المثل: هدى عادل عبد الحمبي *

نشر في: 31 آب 2019

الخلاصة ـ تعد السياحة جانب اقتصادي ومحرك حقيقي للتنمية بشكل عام في العديد من الدول. وتكمن أهمية هذا الجانب في تتمية قطاعات

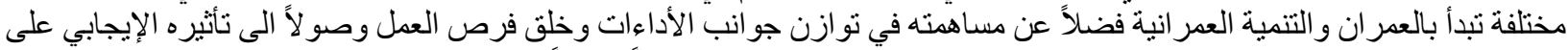

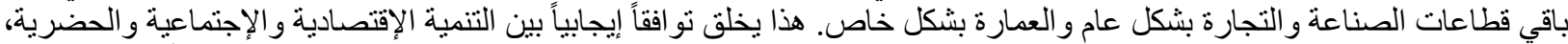

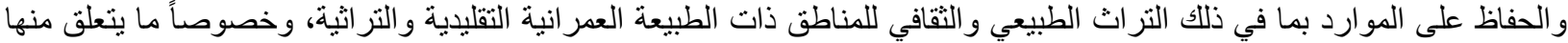

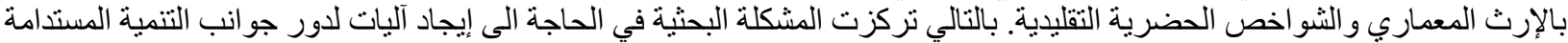

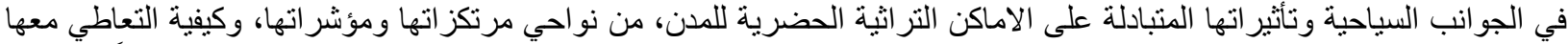

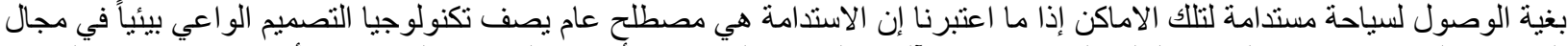

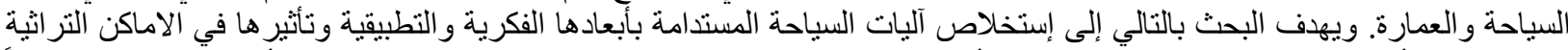

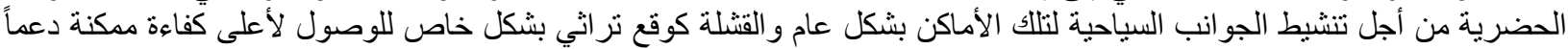
للتنمية المستدامة فيها على المدى الطويل فيما يخص تطور اتها وآثار ها المختلفة (الاجتماعية و البيئية و الاقتصادية) الكلمات الرئيسية ـ السياحة المستدامة، الأماكن التراثية، جو انب التنمية، الإرث المعماري، تكنولوجيا التصميم الواعي.

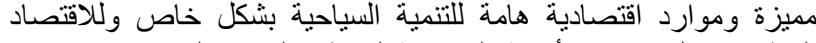

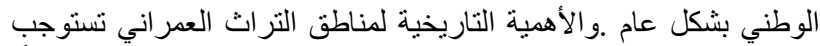

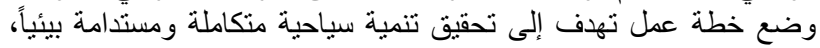

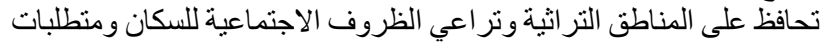

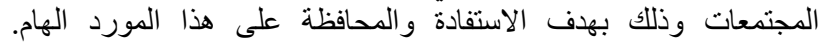

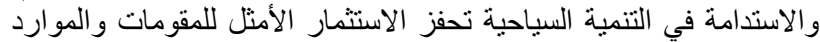

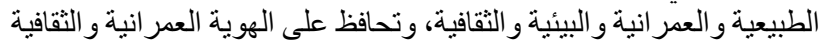

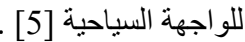

ويتمثل التراث المعماري بمعناه الثامل في العناصر الآتية: - ل

1 - بيئة مكانية شاملة: كتجمع عمر اني أو مدينة عامرة أو مهجورة.

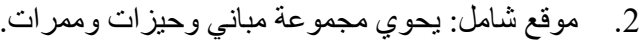

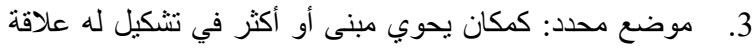

بصرية معينة.

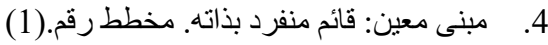

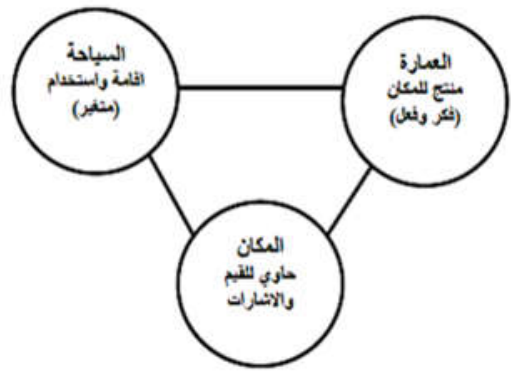

مخطط (1): ثلاثية العمارة و السياحة و المكان[10]
1

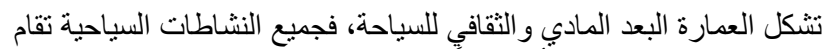

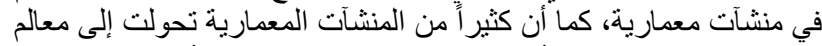

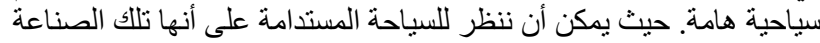

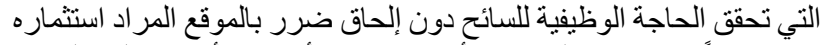

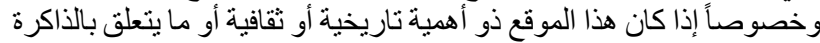
الجمعية المتوارثة للمجتمع. التفرعات المدات المدرجة لاريخة لاحقا هي امثلة للترقيم في بالذاكي

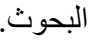

السباحة

.2

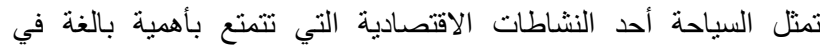

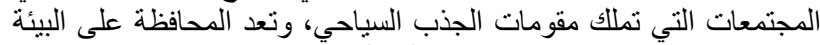

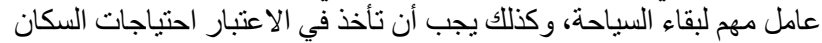

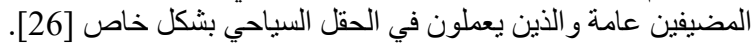

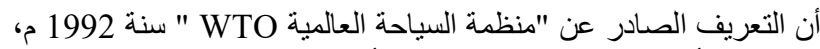

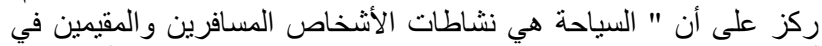

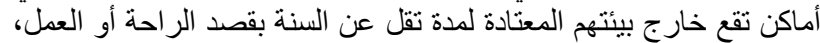

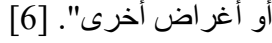

$$
\text { السياحة في الاماكن الحضرية (التراثية) }
$$

تعد عناصر التراث المعماري من أهم عناصر الجذب بالنسبة للسياحة العالمية

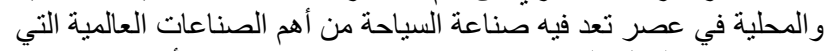

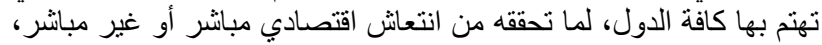

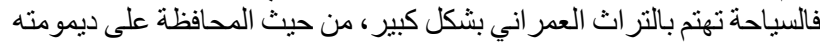

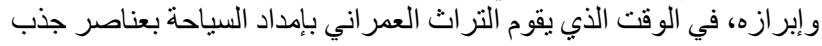




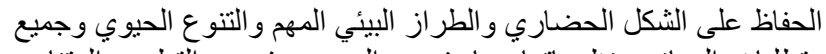

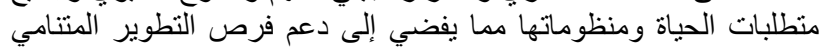

[6] للوجهة

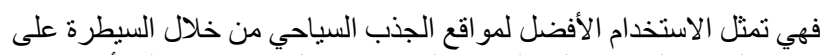

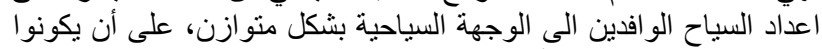

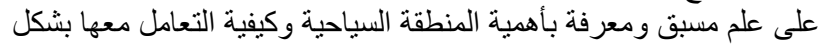
واعي، لضمان منع وقوع الأضر ار على الجهنين [20]

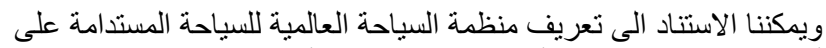

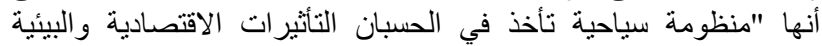
والاجتماعية في المجتمعات المستقبلة للسياح [13 فيان

وقد بسميها البعض بالسياحة المتواصلة اي ضرورة تحقيق الانسجام

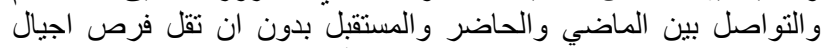

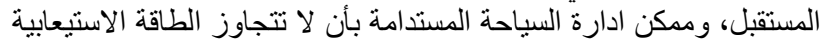

اللبيئة [17]

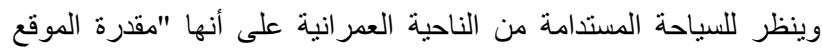

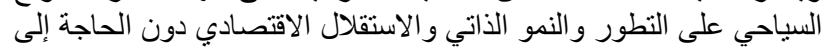

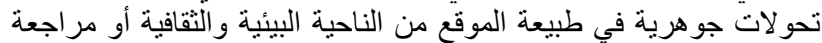

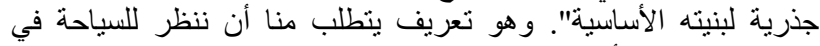
مستويات عمر انية أربعة [22] : مونية

او لاً: مستوى التخطيط الوطني العام: الذي يتضمن تأسيس رؤية وطنية شاملة

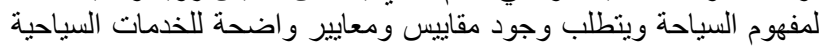

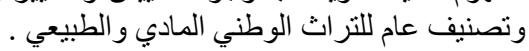

ثانياً: مستوى التخطيط الإقليمي: ويركز على الإمكانيات السياحية المتوفرة

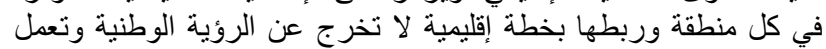

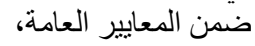

ثالثاً: مستوى التصميم الحضري: وهو مستوى يدعم الخصوصية السياحية

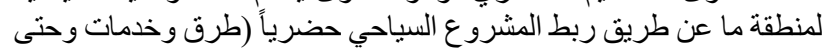

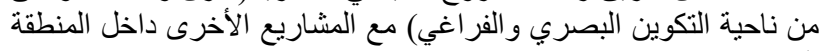
الو احدة.

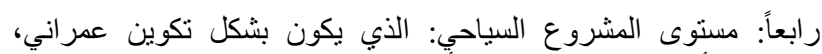

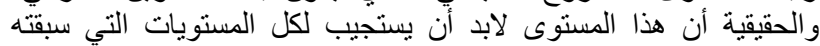

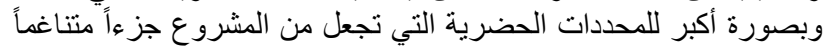
مع البيئة التي حوله [22]

ونظر اً لكل مما سبث فالسياحة المستدامة هي السياحة التي تتميز بالديمومة

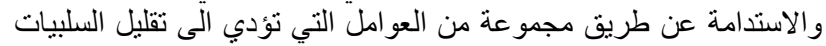

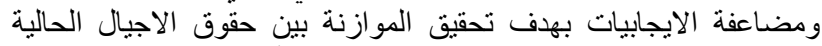

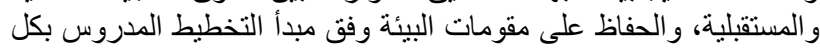

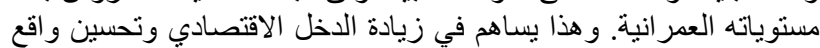
المجتمع المحلي.

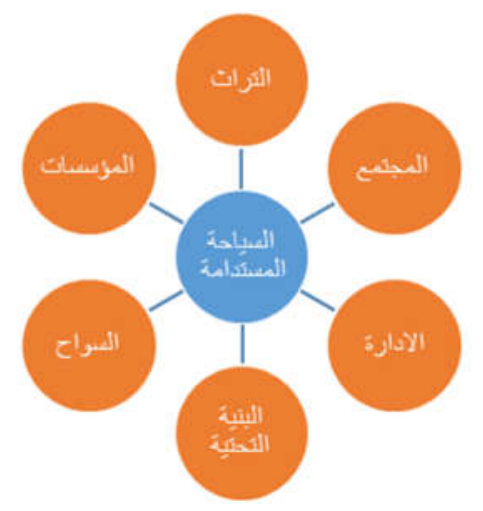

مخطط (2): يوضح ابعاد السياحة المستدامة ـ المصدر: الباحثان

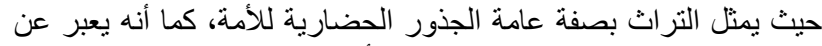

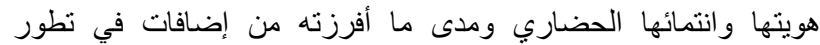

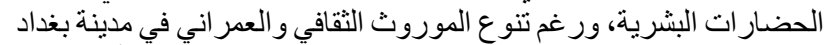

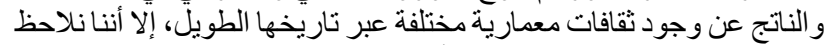

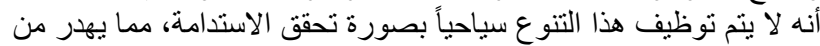

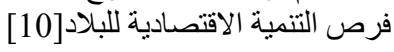

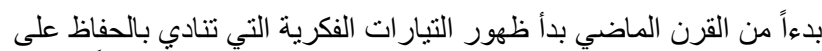

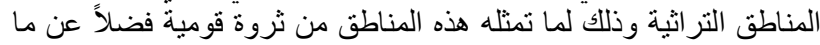

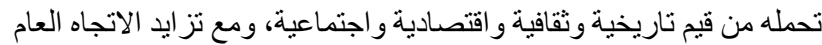

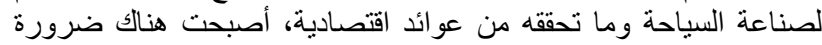

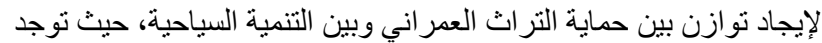

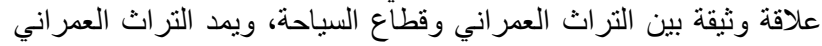

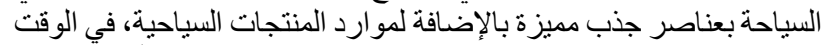

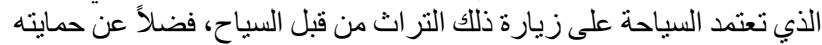

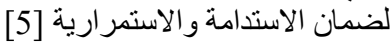

وتؤثر الثقافة والتر اث الثقافي على هوية الناس واحتر امهم الذاتي وكر امتهم.

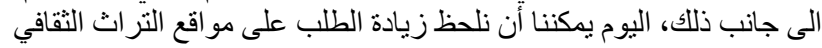

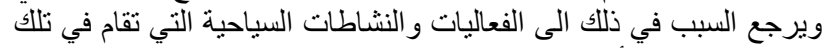

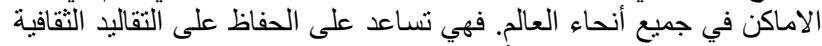

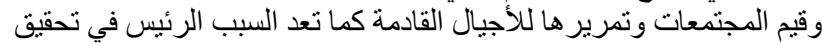

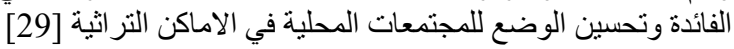

السياحة ليست جديدة في الاماكن التاريخية، كما تعد الامكانات التاريخية

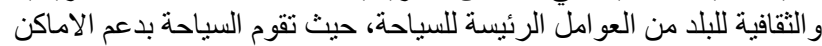

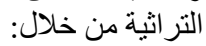

• رفع القيمة الاقتصادية للمكان التراثي مما يسهم في زيادة الدخل القومي و الاقليمي و المحلي القئي

• اعادة توظيف المبنى التر اثي المهجور بشكل منتج.

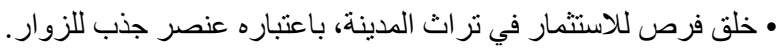
• تشجيع استخدام الخدمات و المر افق المحلية.

• المساعدة في الحفاظ على الموروثات و الذاكرة الجمعية المحلية.

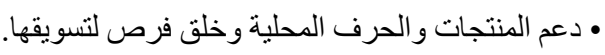

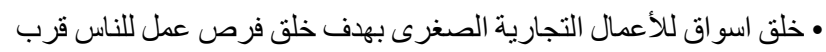

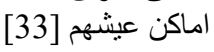

اما بالنسبة لدور الاماكن الترثية في السياحة فيظهر من خلال: • تعد من الوسائل الهامة لإشرالك السياح للتعرف على التراث التاريخي و الثقافي للبلد و الذي يعد اقوى حافز لإند سياحي.

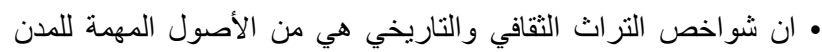

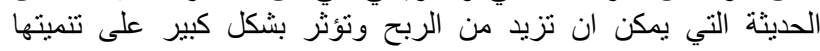
الاقتصادية. • لها اهمية كبيرة في المجال الاجتماعي، وتلعب دور كبير في التوزيع السياحي داخل المدينة.

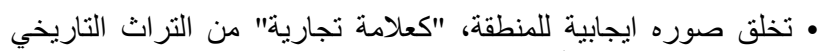

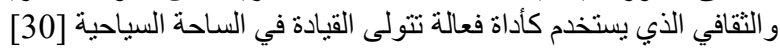

و عليه تندمج السياحة مع حضارة المجتمع و إرثها المكاني، ولذلك فإنها ترتبط

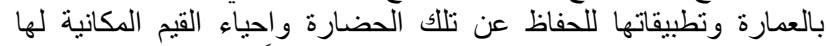

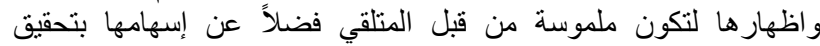
الاستمر ارية التاريخية و التو اصل المجنمعي و الحضاري.

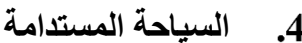

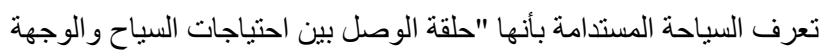

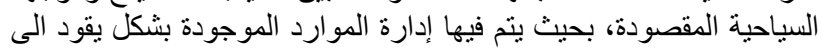

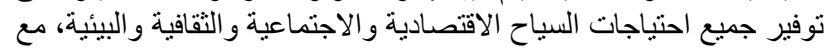


11. تحث على استخلاص معايير للتقويم البيئي ودراسة التأثنيرات

السلبية للسياحة [34]

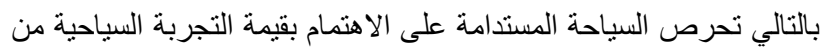

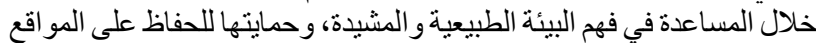
الأثرية و المباني التاريخية و المساهمة في تكاليف الطيدة الحفاظ عليها.

\section{7. التنمية السياحية المستدامة}

تشير وثيقة "مستقبلنا المشترك" الصادرة عن المؤتمر العالمي للبيئة و التنمية

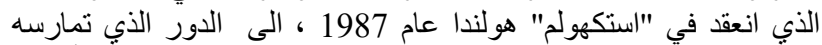

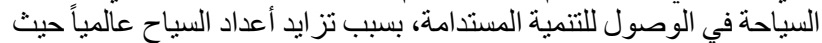

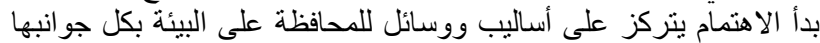

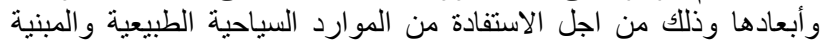

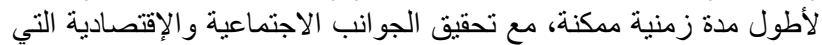

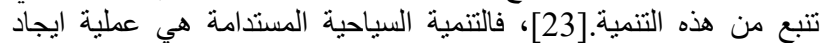

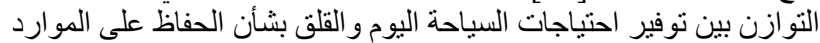

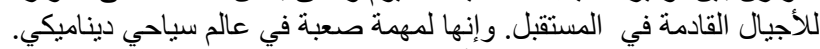

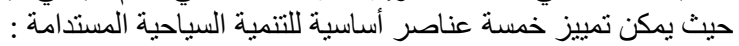
1 ـالحفاظ على مصادر الموارد الموجودة للأجيال القادمة في المستقبل . 2 ـالمحافظة على إستمر ارية انتاج الموارد. 3 ـضمان تحقيق المساو اة ضمن الجيل الو احد ومع الاجيال القادمة. 4 ـالحفاظ على التراث (الثقافي و التاريخي) للمكان أو للمنطقة وحمايته. 5 ـالمحافظة على التنوع الإحيائي وتجنب حدوث تغيرات في المنظومة البيئية [4]

وتعرف التنمية السياحية المستدامة والمتوازنة على انها "تنمية يبدأ تنفيذها

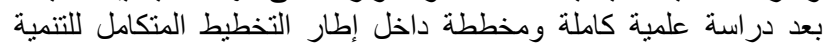

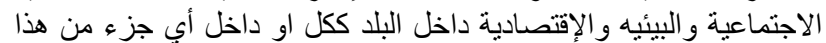

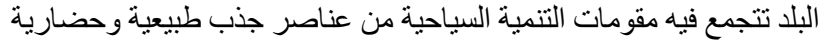

او كليهما [14]

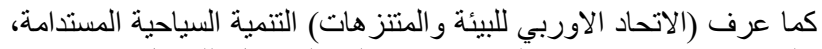

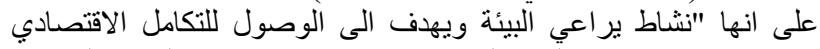

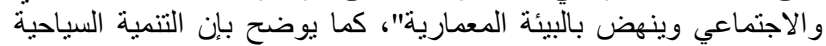

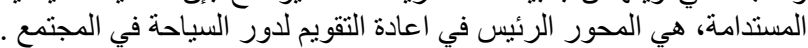

وبالاستناد الى تعريف منظمة السياحة العالمية (UNWTO)* فان التئة التمية

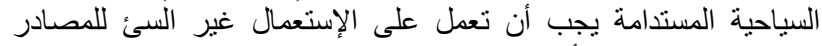

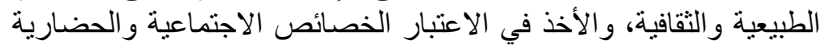

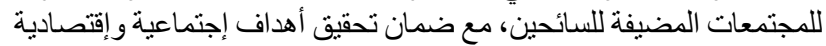
وبيئية لجميع الأطر اف على المدى الطويل [18 ان مستقبل قطاع السياحة يعتمد على حماية البيئة

من التلوث والتدمير والاستخدام غير الرشيد للموارد الطبيعية والتراثية، ولذلك فقد طورت منظمة السياحة العالمية ارشادات يمكن اتباعها للفيرات

$$
\text { عند رسم سياسة للتنمية السياحية المستدامة في }
$$

شكل "مبادئ السيــاحة العالمـية"، Criteria"

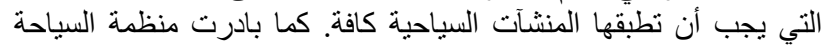

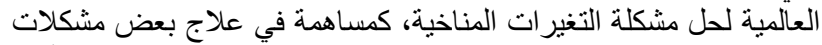
الانبعاث الحر اري و التغيرات المناخية وتطبيق تقنيات رفيقة بالبيئة، من أجل ملئل
5.

تتمثل أهم هذه الخصائص فيما يلي :

• سياحة تهنم بنو عية الخبر ات وطرق تقديمها.

• سياحة فيها عدالة اجتماعية باشتراك الثئ الثعب بصنعها ومعرفة حاجات

السكان.

• سياحة تستخدم المحليين في الأعمال و التخطيط وصنع القرار .

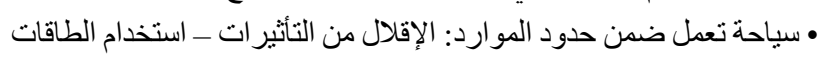
-معالجة النفايات -إعادة الاستخدام.

• سياحة تقدم إمكانية الاستجمام وفرص المعة الاستخرفة والثقافة للأجيال الحالية و القادمة

• سياحة تسمح للضيف أن يستمتع ويجد ما ينشده إلى جانب حماية المجتمع المضيف والبيئة

• سياحة تتوازن مع الصناعات الأخرى والأنشطة ضمن إطار الاقتصاد الوطني

• سياحة تتكامل مع الخطط المحلية و الإقليمية و العالمية [30]

6. اهداف السياحة المستدامة

تشجع السياحة المستدامة على :

1. حماية البيئة والاهتمام بالموارد الطبيعية والموروثات الثقافية

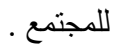

2. تحقيق العدالة على مستوى الجيل الواحد وكذلك بين الأجيال

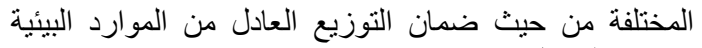

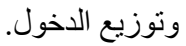

3. خلق فرص جديدة للاستثمار وبالتالي فرص عمل ومصادر دخل

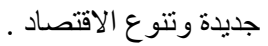

4. الارتقاء بمستوى تسهيلات الترفيه و الخدمات السياحية كالفنادق

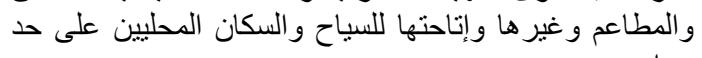
سواء.

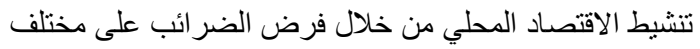

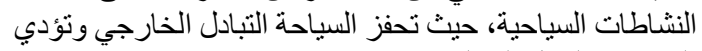

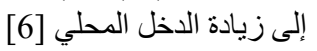

6. تشجع السياحة المستدامة على تحسين وسائط النقل الصديقة للبيئة

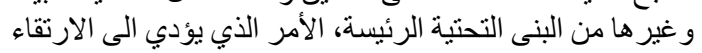

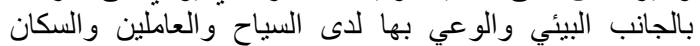
المحليين.

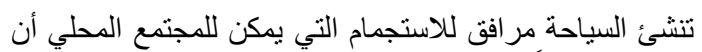

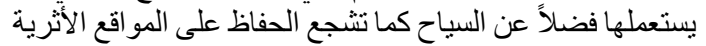
و المباني و المناطق التاريخية وتساهم في تكاليف الكيأ الحفاظ عليها.

8. تشجع على الاستخدام الأمثل للأرض وإستغلال المساحات الارضية وتخطيطها بما يتلاءم مع البيئة الخارجية الإنية المحيطة.

9. تعزز السياحة المستدامة التقدير الذاتي للجماعات المحلية وتسمح بفهم أكبر وتو اصل أفضل بين شعوب من خلفيات مختلفة.

10. تظهر السياحة المستدامة الصديقة للبيئة أهمية الموارد الطبيعية

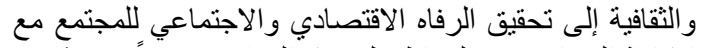

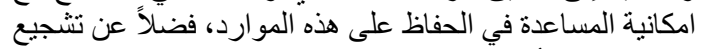

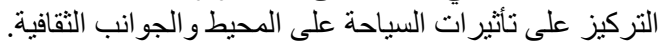




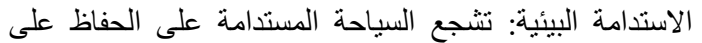

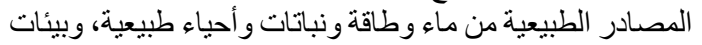

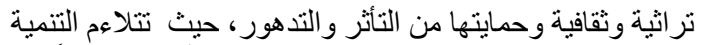

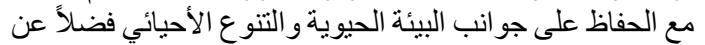

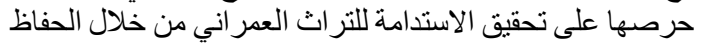

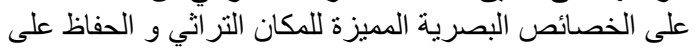

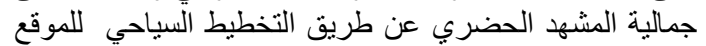

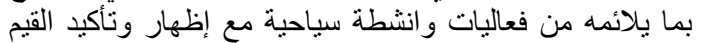

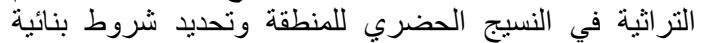

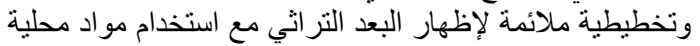

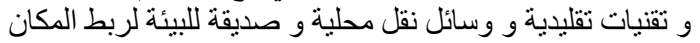

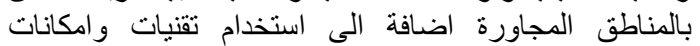
تكنولوجية حديثة في تنسيق وادارة البيئة.

التخطيط الحضري السياحي في تنمية المناطق التراثية

يسهم التخطيط السياحي في تنمية وتطوير مناطق التراث بغرض تأهيلها

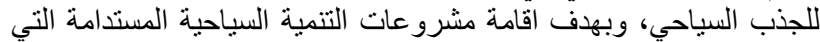

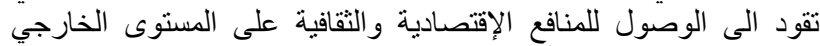

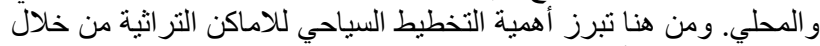

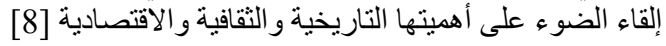

حيث يعمل التخطيط السياحي الناجح على تأكيد الإيجابيات، و العمل على ذلى

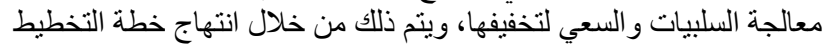
السياحي المستدام الذي يعمل على ما يلي:

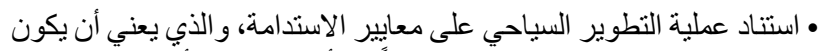

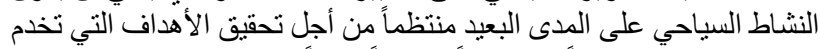

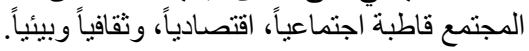

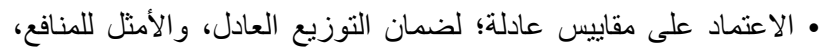

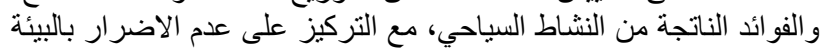
السياحية المقصودة و المجتمع المحلي.

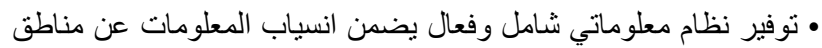

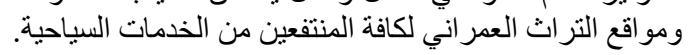

• إنجاز در اسات الجدوى في صناعة السياحة على أن تكون هذه الدر اسات

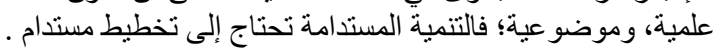

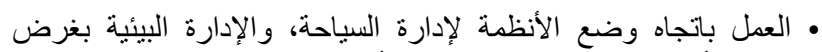

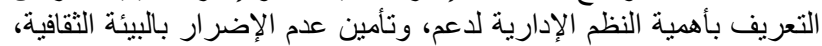
والطبيعية، وجميع مكوناتها [22]

التأثنيرات الإيجابية للتخطيط السياحي المستدام في البيئة تتمثل فيما يلي :

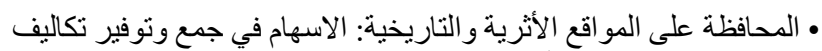

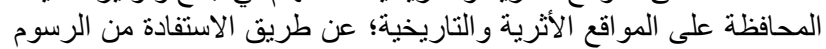

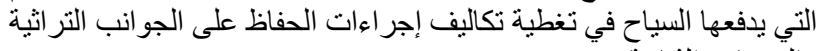
و المصنادر الثقافية.

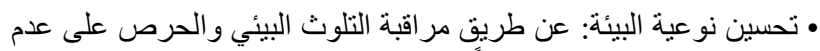

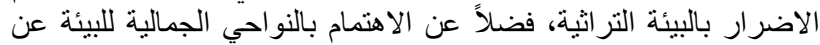
طريق بر امج تنسيق المو اقع وصيانتها و الحفاظ عليها.

• الحفاظ على القدرات التحميلية لمو اقع التراث مر اعاة القدرات التحميلية للاماكن التر اثية بحيث تثناسب التراث (carrying capacity)

أعداد السياح مع قدرتها التحملية.
حماية البيئة والجوانب السياحية من التلوث. ان التنمية السياحية المستدامة جانب ذو فعالية في المحافظة على الارثة البئة الثقافي و التاريخي للأمة.

وكمصدر هام للاخل القومي فان قطاع السياحة يرتكز على الثقافة الوطنية

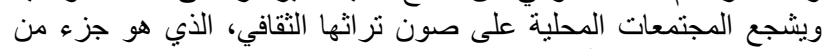

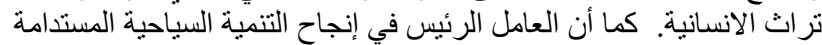

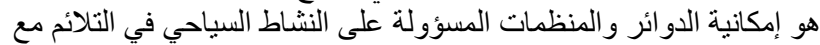

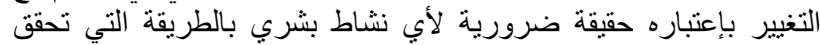

الاستدامة بكل جو انبها [22]

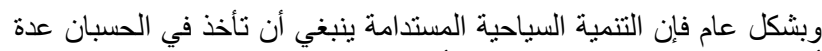

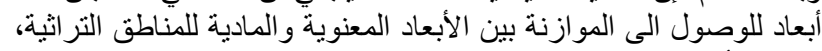

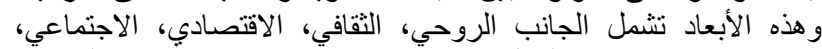

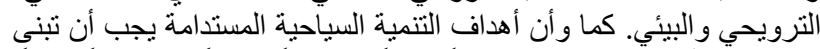

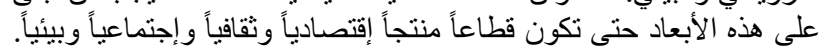

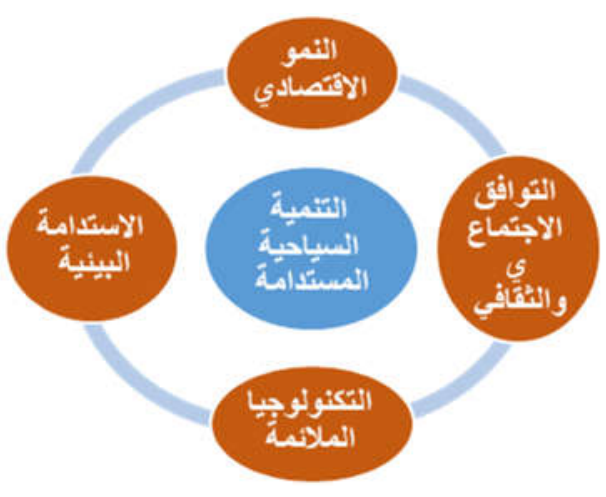

مخطط (3): المبادئ الاربعة للتنمية السياحية المستدامة

المصدر: (United Nations Environment Programme on Tourism)

(UNWTO) United Nations World Tourism) (Organization

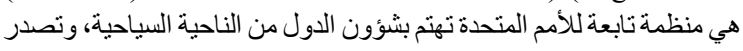
الإحصائيات المتعلقة بالطلب و العرض السنابعة السياحي على مستوى العالم.

8

وضع الاتحاد العالمي للحفاظ على البيئة نهجاً تصورياً لتنمية السياحة

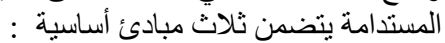

1. الاستدامة الاقتصادية: تعد التنمية السياحية المستدامة في الوجهة

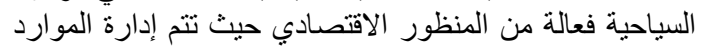

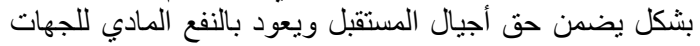

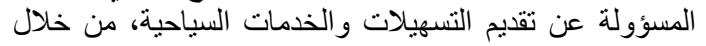

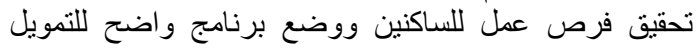
كالإنفاق الحكومي او الاستعانة بالمنظمات المنات المعنية بالسياحة

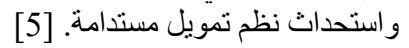

الاستدامة الاجتماعية والثقافية: تؤكد إلى أن هذه المنظمات

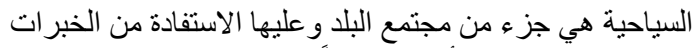

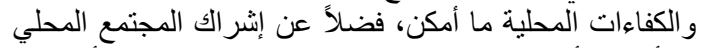

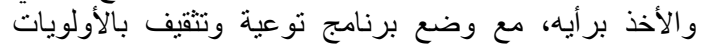

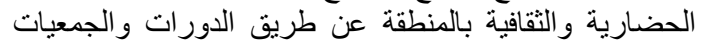

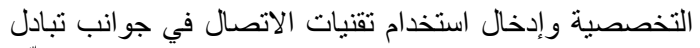
الخبرات بين المؤسسات المختلفة المهنمة بالسياحة بمات بمات بمكّن

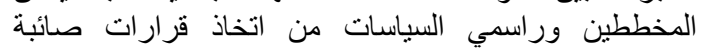

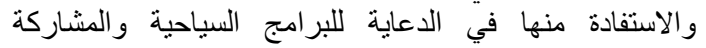
المجتمعية في الحفاظ على المصادر الطبيعية والتاريخية وإدادية وادئها.

[12] 
التتموية، وإحتواء أية آثار بيئية سالبة. [8]

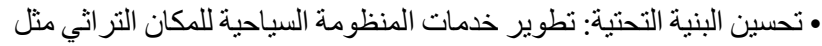

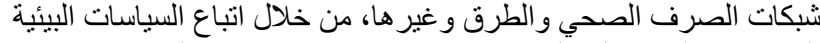
المستدامة والتي تعمل على توفير بنية تحتية قوية، وتطبيق الرقابة المبابة

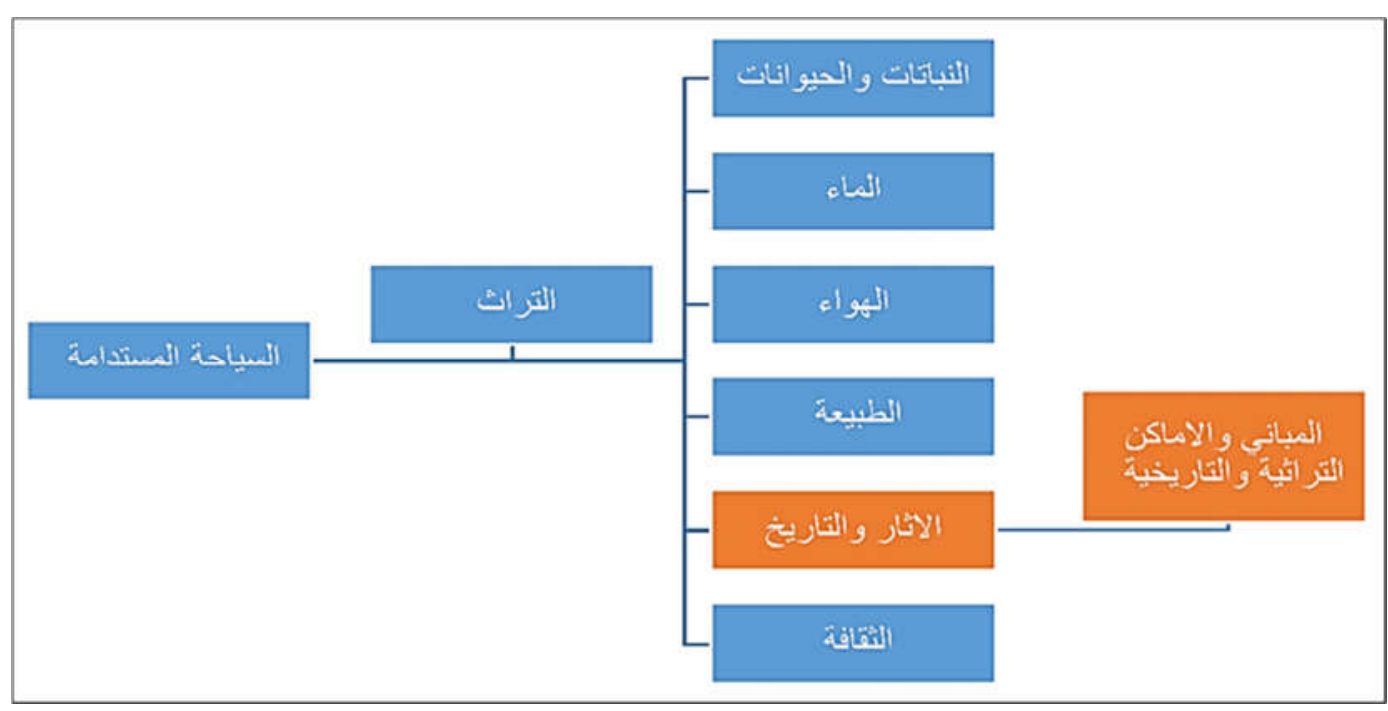

مخطط (4): نموذج يوضح علاقة السياحة المستدامة بالأماكن التز اثية، المصدر (الباحثان)

على نهر دجلة مما يشير الى الامكانيات الواسعة لهذا المبنى لغرض اقامة

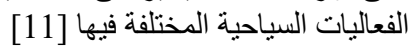

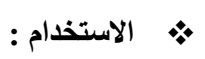

يعود تاريخ بناء القثلة إلى بداية سنوات حكم الو الي نامق باثنا (1851-

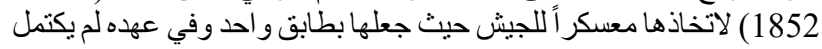

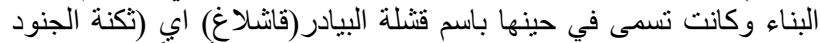

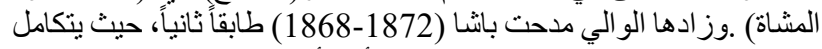

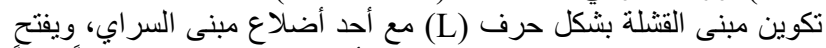

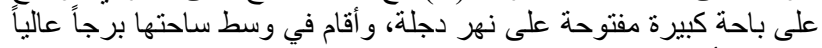

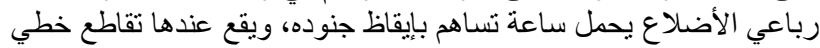

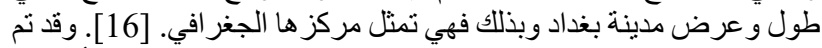

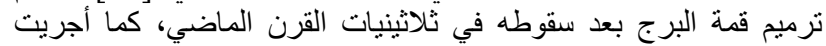

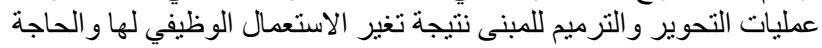

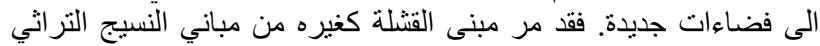

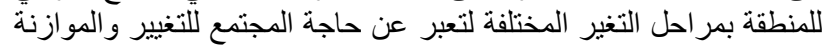

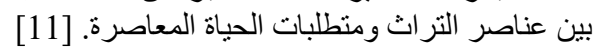

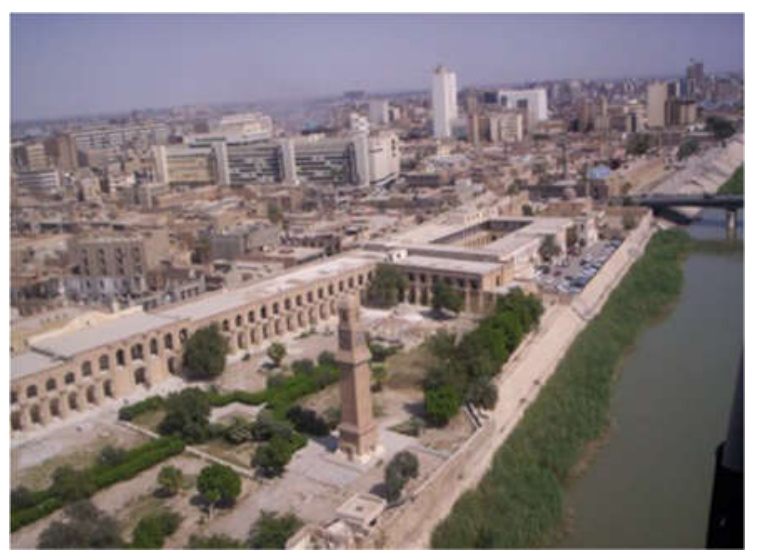

الشكل (1): القثلة

http://www.panoramio.com/photo/32687242:المصدر
10. استخدام المؤشرات البيئية في السياحة المستدامة

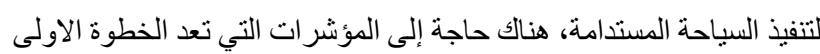

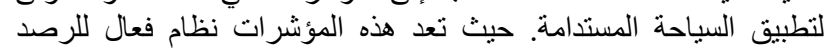

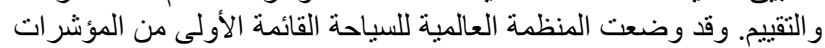

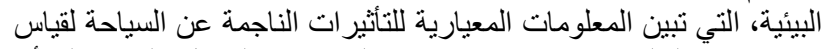

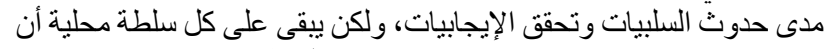

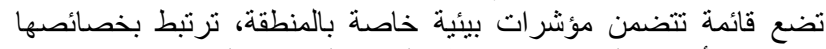

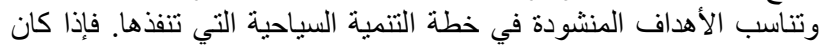

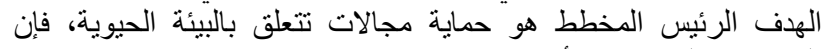
المؤشر ات البيئية يمكن أن تكون [33] :

• تلك التي تقيس مساحة المنطقة.

• تلك التي تقيس مدى التدهور في التنوع الحيوي و الخلل في الثروط الطبيعية

• و إذا كان الهدف هو دعم النوعية للمراكز الأثرية والمواقع التاريخية

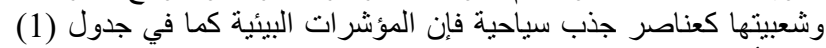

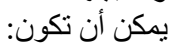

• تللك التي تقيس حماية البيئة وتكاملها مع موارد الموقع. • تللك التي تقيس مدى رضا الزوار وتبين توجهاتهر.

11. الحالة الدراسية: القثلة

يعد مبنى القشلة من المباني المهمة و الذي يعد من أثشر الأبنية التراثية في بغداد التي تعود الى حقبة التمكم العثماني.

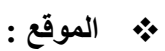

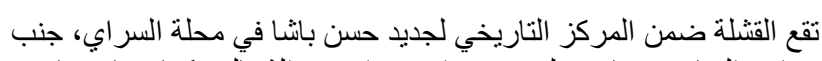

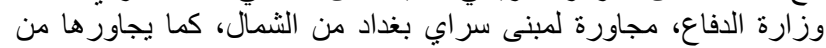

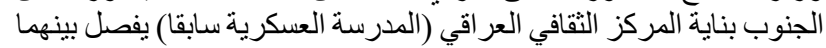

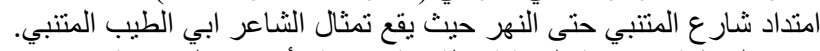

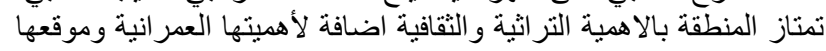


جدول (1): يوضح المؤشر ات المستخلصة من قبل منظمة السياحة العالمية للوصول الى السياحة المستدامة [33] بتصرف الباحثان

\begin{tabular}{|c|c|}
\hline 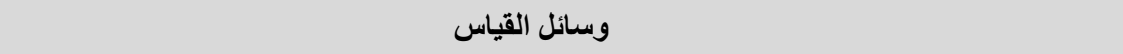 & المؤشرات \\
\hline \multicolumn{2}{|l|}{ 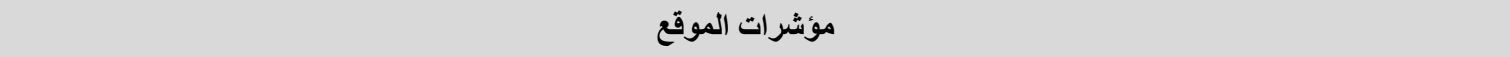 } \\
\hline توزيع مجالات الحماية وفق تصنيفات الاتحاد الدولي لحماية الطبيعة والموارد الطبيعية (IUCN) & 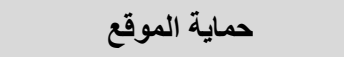 \\
\hline اعداد الزوار الذين يزورون الموقع (سنوياً / فترة الذروة) & الضغط \\
\hline وجود خطة إقليمية منظمة للسياحة (تضم مكونات السياحة) & عملية التخطيط \\
\hline 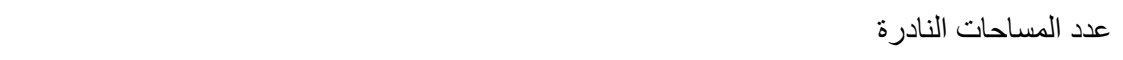 & نظم البيئة الحساسة \\
\hline وجود إجر اءات للمر اجعة البيئية وضو ابط رسمية خاصة بتطوير الموقع وبكثافة الاستخدام & السيطرة على التنمية \\
\hline نسبة النفايات التي يتم معالجتها من المواد الداخلة. & إدارة النفايات \\
\hline \multicolumn{2}{|l|}{ مؤشرات الاستخدام } \\
\hline كثافة الاستخدام في موسم الذروة (شخص / هكتار ) & كثافة الاستخدام \\
\hline نسبة السياح إلى السكان المحليين (فترة الذروة والاوقات الاخرى) & 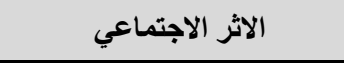 \\
\hline مستوى رضا السياح (حسب الاستبيان) & المقبولية للسياح \\
\hline مستوى الرضى للسكان المحليين (حسب الاستبيان) & 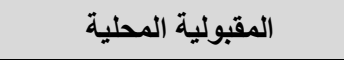 \\
\hline نسبة النشاط الاقتصادي الكلي الى النشاط الناتج عن السياحة & مساهمة السياحة إلى الاقتصاد \\
\hline \multicolumn{2}{|l|}{ مؤشرات مركبة } \\
\hline معايير المؤشرات تسمح مبكرًا بالتحذير من تجاوز الحدود لمختلف شرائح الزوار وفق استطاعة المكان & طاقة الاستيعاب \\
\hline المعايير المركبة للتأثير ات على الموقع (طبيعية وثقافية) & ضغوط على الموقع \\
\hline مقاييس الجودة في مشوقات الموقع تجعلها جاذبة للسياحة ويمكن تطوير ها & تحريض الطلب \\
\hline
\end{tabular}

جدول (2): يوضح المؤشر ات لتطبيق السياحة المستدامة الاماكن التر اثية المصدر (الباحثان) استنادا الى الدراسات ـ مصدر الصور (الباحثان)

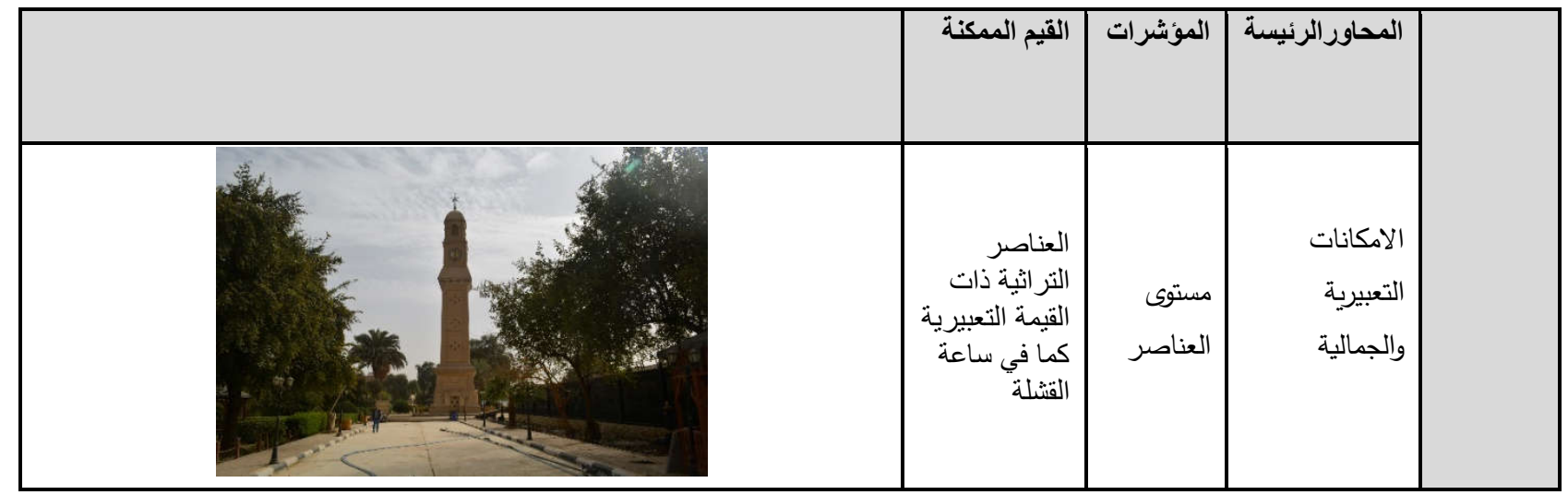




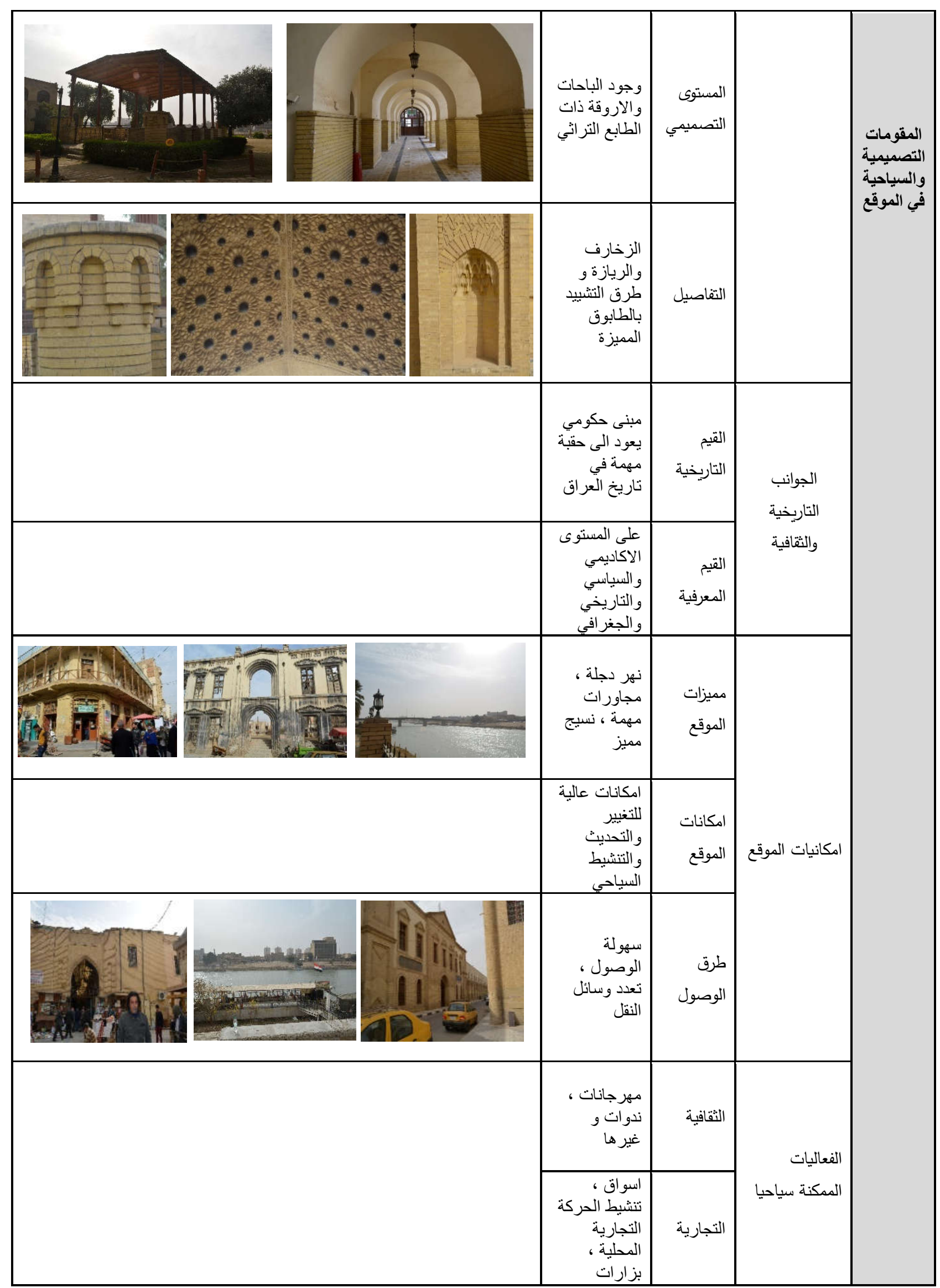




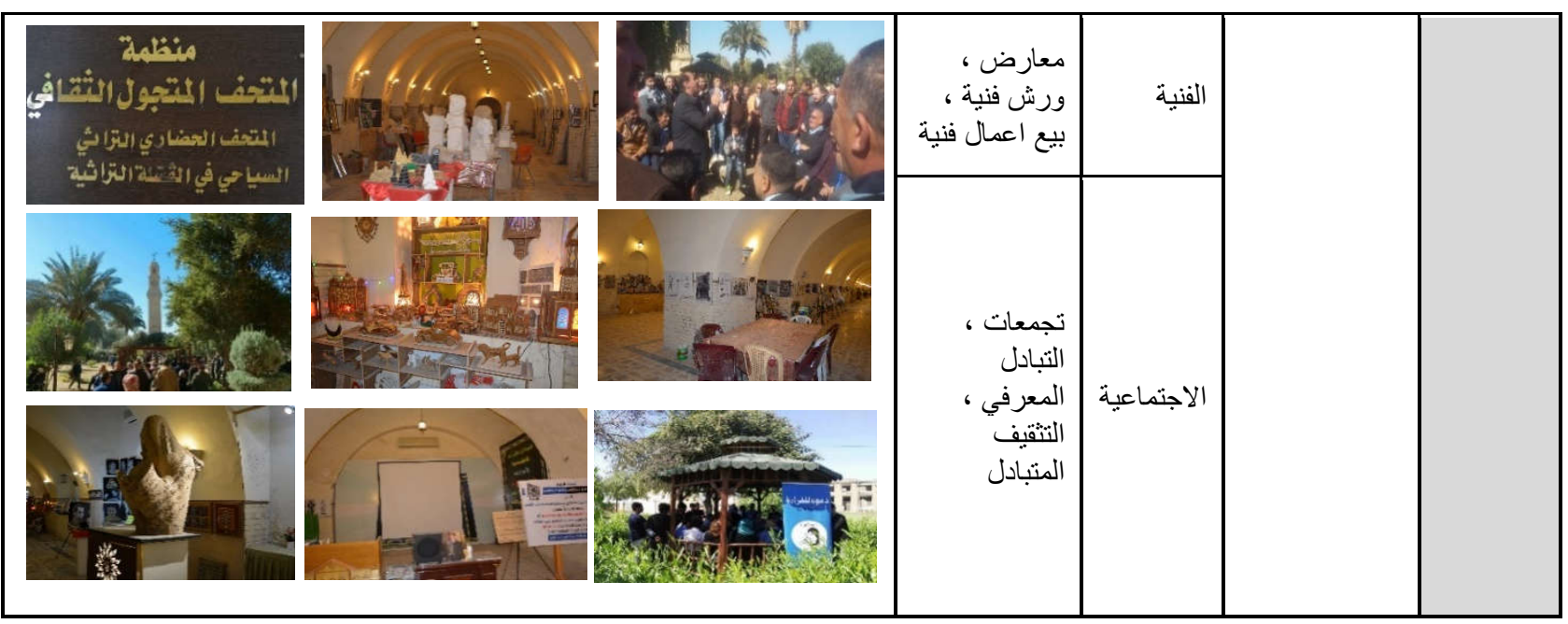

13. الإستنتاجات المستخلصة من الإطار النظري

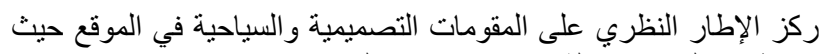
إرتبط هذا الجانب بجملة من الإمكانيات و الجوانب منها:

الجانب الأول: الإمكانيات التعبيرية والجمالية: والتي إثتملت على جملة من

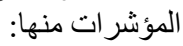

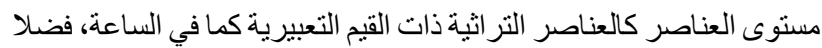

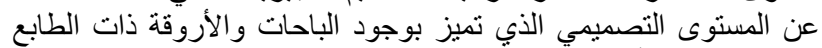

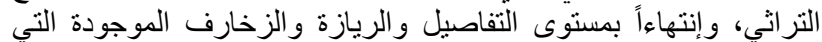
تعطي مميز ات تلك الحقبة من نو احي المو اد والتنفيذ.

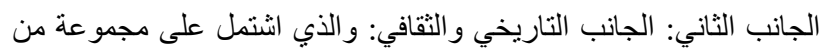

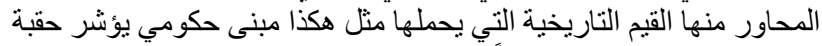

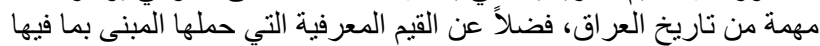
من جو انب اكاديمية وتاريخية وجغر افية.

الجانب الثالث: إمكانيات الموقع: و التي افضت الى عدة مميز ات منها مجاورة

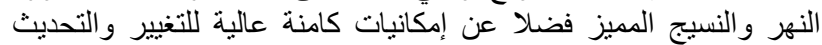
و التطوير ، وما ارتبط بها من سهولة الوصول وتعدد وسائط النقل.

الجانب الرابع: الفعاليات المككنة سياحياً: وهذه تتدرج تحتها الفعاليات المتاحة التي من المكن أن يتصف بها الموقع ومنها:

• الفعاليات الثقافية: إقامة المهرجانات و الندوات والمعارض

• الفعاليات الفنية: المعارض والورش الفنية والتعليمية وعرض الفئل النتاجات الفنية بكل أنو اعها.

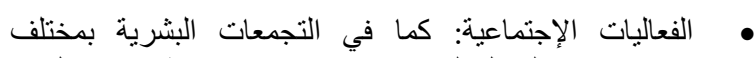
تخصصاتها و التبادل المعرفي وما ينتج عنه من تثقيف منبادل. لئن
بعد الاحتلال البريطاني اتخذوا من القثلة عام 1917 مسكنا للضباط

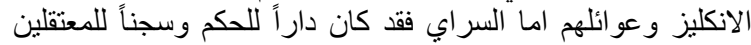

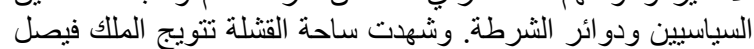
الأول ملكاً على العراق في 23 أغسطس /آب 1921 [25] .

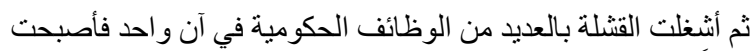

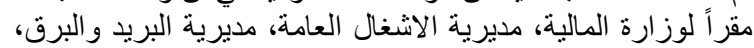

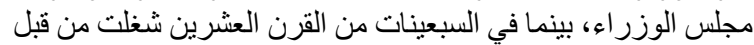

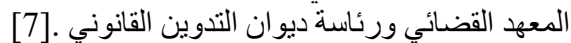

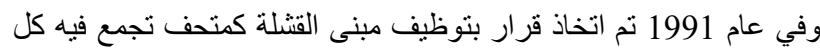
الوثائق عن فعاليات إعادة الإعمار التي جرت بعد الحرب عام 1991.

وبعد عام 2003 تعرض المبنى لأعمال تخريب وسلب إضافة إلى الأضر ار

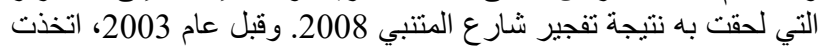

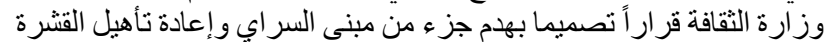

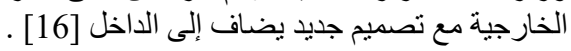

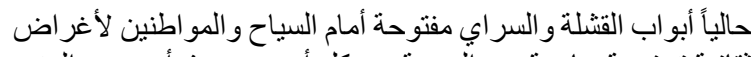

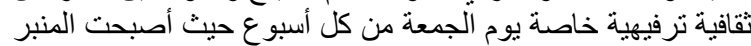

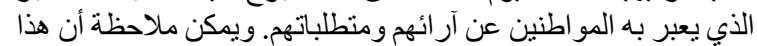

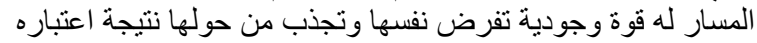
شاهد على التاريخ و إحتو ائه العديد من الأبنية ذات القيمة التر اثثية. [25]

12. مفردات الإطار النظري

وضع البحث جملة من المؤشر ات مثلت المحاور الرئيسة التي تجسد إمكانيات تطبيق السياحة المستدامة في مبنى القثّلة التراثي وكما هو موضين التي في جدول 
جدول (3): يوضح مؤشرات تطبيق محاور الإستدامة المصدر : (الباحثان)

\begin{tabular}{|c|c|c|c|}
\hline القيم الممكنة & & المؤشرات & \multirow{19}{*}{ محور الاستدامة } \\
\hline محلية معاصرة & \multirow{4}{*}{ المواد } & \multirow{7}{*}{ الاستدامة البيئية } & \\
\hline محلية تقليدية & & & \\
\hline قديمة تر اثية & & & \\
\hline حديثة تكنولوجية & & & \\
\hline الاضـاءة & \multirow{3}{*}{ التقنيات } & & \\
\hline التنفيذ & & & \\
\hline وسائل صديقة للبيئة & & & \\
\hline جدوى اقتصادية & \multirow{2}{*}{ تتمية الموارد } & \multirow{7}{*}{ الاستدامة الاقتصادية } & \\
\hline تخطيط اقتصادي & & & \\
\hline تشغيل عمالة محلية & \multirow{2}{*}{ تنمية الطاقات } & & \\
\hline توفير تسهيلات سياحية & & & \\
\hline قطاع حكومي & \multirow{3}{*}{ التمويل ل } & & \\
\hline قطاع خاص استثماري & & & \\
\hline $\mathrm{NGO}$ & & & \\
\hline بر امج التو عية المجتمعية & \multirow{2}{*}{ تنمية الوعي } & \multirow[t]{4}{*}{ الاستدامة الاجتماعية } & \\
\hline التو عية السياحية للزوار & & & \\
\hline المشاركة المجتمعية & \multirow{2}{*}{ المشاركة الاجتماعية } & & \\
\hline تبادل الخبرات & & & \\
\hline
\end{tabular}

\section{5. التوصيات النهائية للبحث}

تتمثل بالهدف الرئيسي لإعادة إستخدام المباني التراثية في الحفاظ على هذه

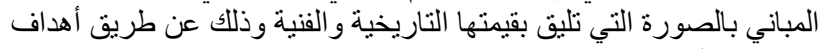

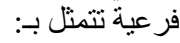

1. حماية المواقع الأثرية والمباني التاريخية و المساهمة في تكاليف الحفاظ

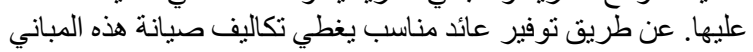
و إيجاد قاعدة إقتصادية.

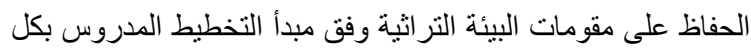

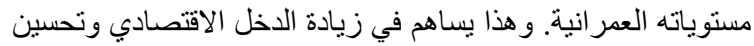

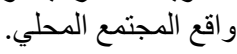

تأسيس رؤية وطنية شاملة لمفهوم السياحة ويتطلب وجود مقاييس و معايير و اضحة للخدمات السياحية وتصنيف لمنيف عام للتر اثلئ الوطني.

$$
\text { 4. إيجاد نوع من التعاطف بين المبنى الأثري و المتعاملين معه. }
$$

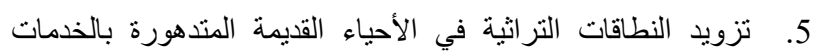
اللازمة لها دون الحاجة إلى إقامة مباني جديدة.

6. إستغلال الآثار بكونها نقاط جذب سياحية وإستثمار ها لتنمية المحيط

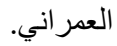

7. إيجاد إنر اف دائم على هذه الأبنية عن طريق المستخدمين و المنتفعين. 8. ضمان إستمر ارية أعمال الصيانة و النظافة.

9. المشاركة في تنمية المجتمع المحيط بما يدعم الحفاظ على الطابع

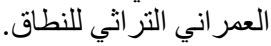

المصادر

[1] محد عبد الفتاح احمد العيسوي. (ديسمبر 2012). "الارتقاء بالنطاقات التراثية ذات القيمة: دراسة مقارنة لسياسات الحفاظ على التراث بلتراث

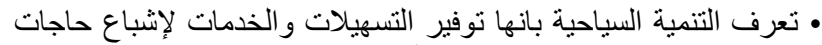

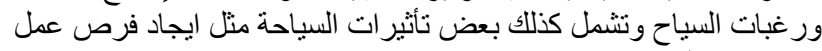
جديدة ودخول جديدة.

• التأثير ات الإيجابية للتخطبط السياحي المستدام في البيئة تتمثل فيما يلي:

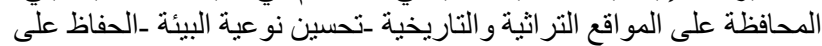

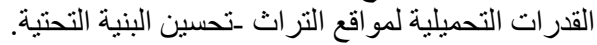

• تقوم السياحة بدعم الاماكن التراثية عن طريق رفع القيمة الاقتصادية للمكان

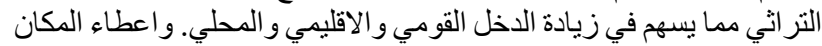

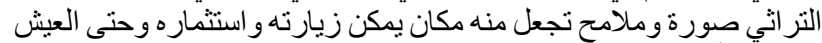

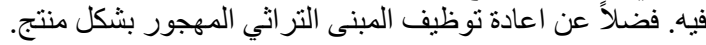

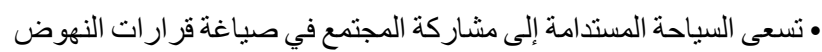

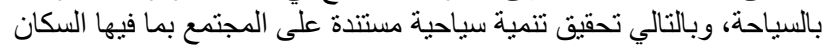

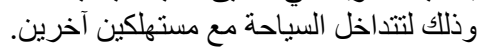

• التتمية السياحية المستدامة ينبغي أن تأخذ في الاعتبار عدة أبعاد لتحقيق

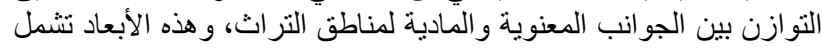

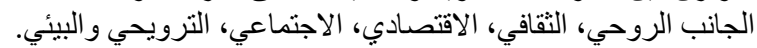

• شواخص التراث الثقافي و التاريخي هي من الأصول المهمة للمدن الحديثة

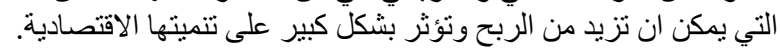

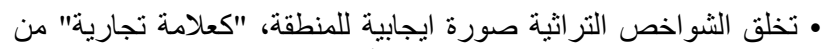
التراث التاريخي و الثقافي الذي بيتخدم كأداة فعالة تتولى القيادة في الساحة السياحية.

• ينظر للسياحة المستدامة من الناحية العمر انية في مستويات عمر انية أربعة:

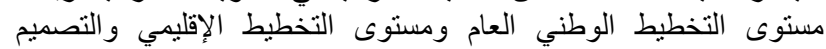
الحضري، و المشروع السياحي كتكوين عمر اني. 
[19] محمد ابر اهيم عر اقي." التنمية السياحية المستدامة در اسة تقويمية

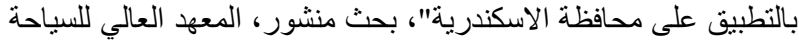
و الفنادق و الحاسب الالي، الاسكندرية - مصر.

[20] محمد محمود عبد الله يوسف. (2015)." آليات تحقيق السياحة

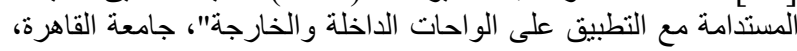
القاهرة - مصر.

[21] محمد منير حجاب. (2003). "الاعلام السياحي"، دار الفجر

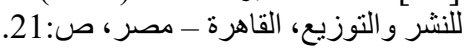

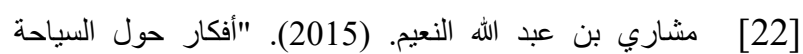
والعمارة". مقالة منشورة، جريدة الرياض، الريم، الرياض-السعودية.

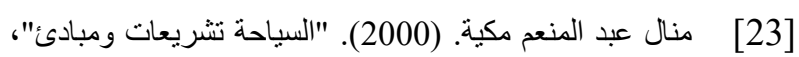
دار صفاء للنشر و التوزيع، عمان-الاردن، صنية.

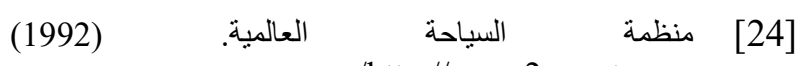
/http://www2.unwto.org

[25] مؤيد الطرفي. (2013)." جريدة القدس العربي. http://www.alquds.co.uk/?p=118271

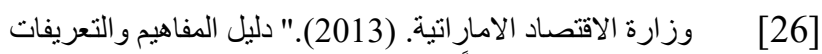

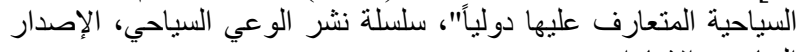

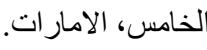

\section{Refrences}

[27] Aronssont L. (2000). "The Development of Sustainable Tourism،" UK: Bass Press ,First edition. London-UK.

[28] Helmy, E. (1999)." Towards Sustainable Planing for Tourism Development: Case Study on Egypt", An International Sustainble Development in Emerging Markets: SustainableDevelopment Forum, George Washington University, Alexandaria- Egypt ,p: 58.

[29] Heritage Office, N. (1999). "Sustainable Tourism and Cultural Heritage ،"A Review of Development Assistance and its Potential to Promote Sustainability, Oslo -Norway.

[30] Ismagilova, Safiullin, Gafurov, G. (2015). "Using historical heritage as a factor in tourism development '"Procedia - Social and Behavioral Sciences, p:158.

[31] Jaini, N., Anuar, A. N. A., \& Daim, M. S. (2012). "The practice of sustainable tourism in ecotourism sites among ecotourism providers" Asian Social Science, p:175-179.

[32] Moscardo, G. (1998). "Inter pertation and sustainable tourism functions examples and principles '"the journal of tourism studies، vol.9 , no.1,p:3.

[33] Regions, E. a. (2009). "Guidelines for Sustainable Cultural Tourism in Historic Towns and Cities" .

[34] Gunn, C.A., Var, (2OO2)." T. Tourism Planing" Routledge, Fourth edition, New York- USA.

[35] W. Swart William. (1970)." Planning for Tourism Development ."New York: Praeger Publishers.

[36] WTO. (1993)." Sustainable Tourisme Developement ,"Guide for Local planning.

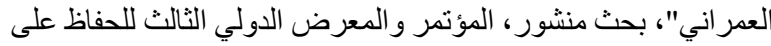

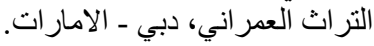

[2] [مد يحيى محمد جمال الدين ر اثد. (2010). "استدامة البيئات التر اثية:

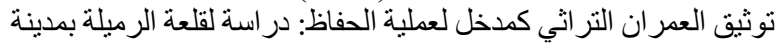

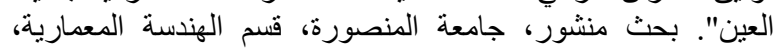

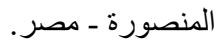

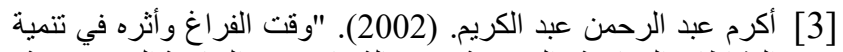

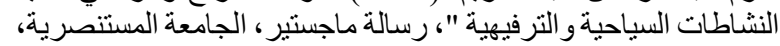

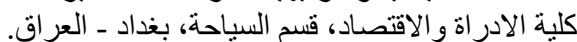

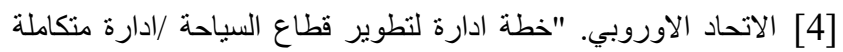

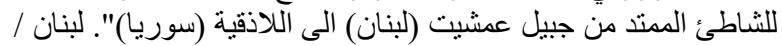
سوريا.

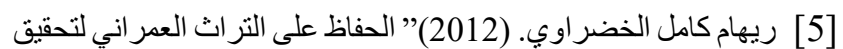

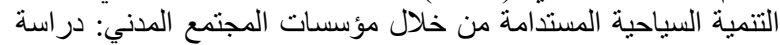

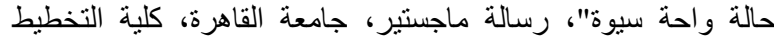

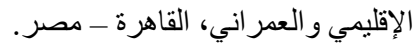

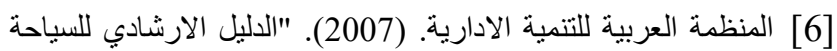
المستدامة في الوطن العربي". الطبعة الاولى، القاهرة-مصر.

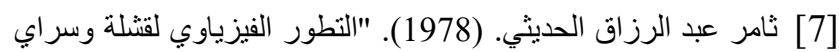

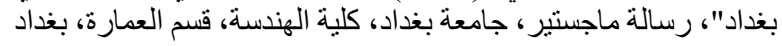

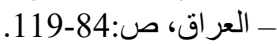

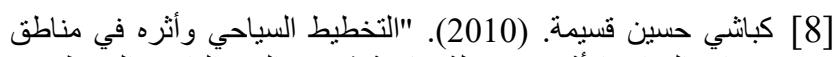

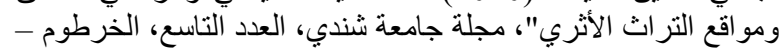

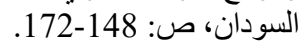

[9] سحر محمود الأرناؤوطي. (148-12001). "الإسكان و الثقافة وعلاقتهم

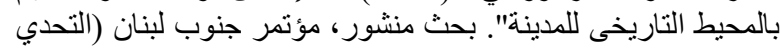

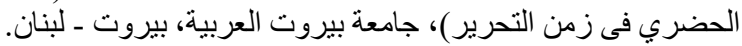

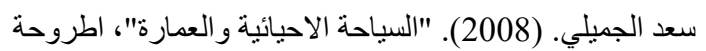
دكتور اة، جامعة بغداد، قسم هندسة العمارة، بغدادـ العر اق.

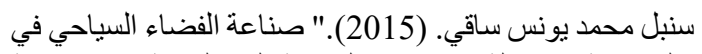

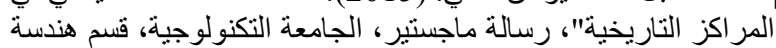

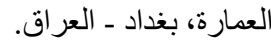

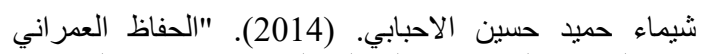

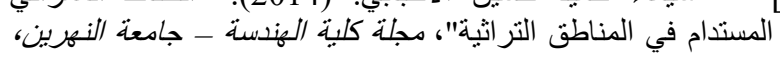

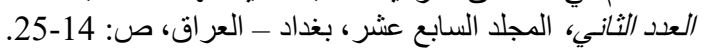

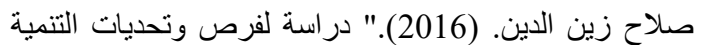

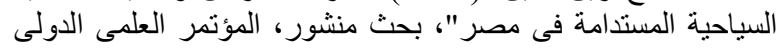

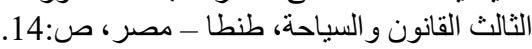

[14] عبد الوهاب صلاح الدين. (1991)." التتمية السياحية"، مطبعة

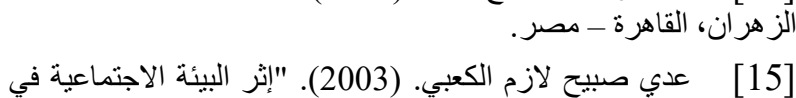

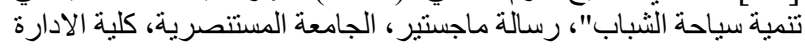
و الاقتصاد، قسم السياحة، بغداد ــ العراقئ

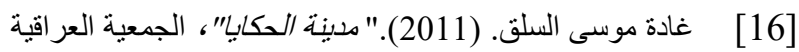

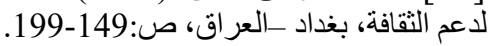

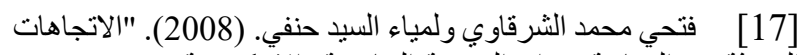

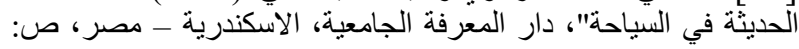

[18] محمد إبراهيم عراقي وفاروق عبد النبي عطا الله. (2010).

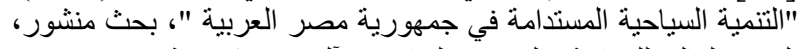

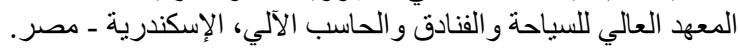




\title{
Sustainable tourism in urban heritage places - Al-Qishlaq as a case study
}

\author{
Huda Adel Abdul-Hameed ${ }^{1}$, and Osamah Abdulmunem Al-Temeemi ${ }^{2}$ \\ ${ }^{1}$ Department of Architecture,University of Baghdad, Iraq, dolaarch@yahoo.com \\ 2 Department of Architecture,University of Baghdad,_Iraq, eng_usama_uat@yahoo.com \\ * Corresponding Author: Huda Adel Abdul-Hameed, email: dolaarch@yahoo.com \\ Published online: 31 August 2019
}

Abstract- Tourism is an economic aspect and a real engine of development in many countries. The importance of this aspect lies in the development of various sectors starting with architecture, urban development, as well as its contribution to the balance of performance and job creation, and its positive impact on the other sectors of the industry and trade in general, and architecture in particular. Architecture forms the physical and cultural dimension of tourism, all tourist activities are held in architectural facilities and many of the architectural facilities have become important tourist attractions. This creates a positive correlation between economic, social, urban development and the preservation of resources including the cultural heritage, especially those related to architectural heritage and traditional urban figures. Where sustainable tourism can be viewed as an industry that fulfills the functional need of the tourist without prejudice the location which to be invested, especially when the site has a historical or cultural significance or even the collective memory of the community. Therefore, the research problem focused on the knowledge deficit in studying the aspects of sustainable development and its role in tourism and its mutual effects on the urban heritage of cities in terms of their points of view and indicators and how to deal with them in order to achieve sustainable tourism for those places, If we consider sustainability is the environmentally conscious in tourism and architecture. The aim of this research is to draw the aspects of sustainable tourism in all its intellectual and applied dimensions and their impact on the urban heritage sites in order to promote these places to achieve the highest possible efficiency for sustainable tourism in the long term, with regard to their developments and their various impacts (social, environmental and economic) on those places.

Keywords - Sustainable tourism, heritage places, development sides, architectural legacy, conscious design technology. 